
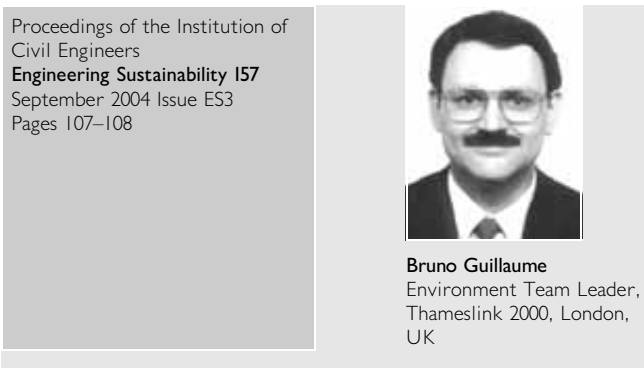

\title{
Editorial
}

\section{B. Guillaume}

On 13 April 2004, the Sustainable Development Commission published its review of the UK Government's sustainable development record in a report entitled 'Shows Promise: But Must Try Harder'. ${ }^{1}$ It recognised efforts to protect the environment, reduce unemployment, alleviate poverty, increase life expectancy and improve education, but also appealed for fundamental policy shifts to improve overall quality of life and tackle a range of issues including waste.

Two months later, on 15 June 2004, the Institution of Civil Engineers issued its report, 'The State of the Nation', ${ }^{2}$ highlighting actions that the Institution's experts believe are needed to improve the UK infrastructure. Awarding a dismal overall grading of D+ to the state of the nation's infrastructure, the report confirmed the message 'must try harder'. The press release emphasised the need for urgent action to address the rubbish mountain.

Waste management features prominently in the sustainable development agenda as it does within the construction sector. According to UK Government figures, the construction industry produces around 92 million tonnes of waste, of which an estimated 13 million tonnes is unused material. In July, the Government issued a new tool for the construction industry in the form of guidance to reduce the amount of waste produced. ${ }^{3}$ The guidance highlights the key to waste minimisation as ensuring that site engineers, surveyors and planning and procurement experts accurately assess the use of materials and the potential for their re-use and recycling both on- and offsite. In other words, 'reduce, reuse, recycle'.

This special issue of the Journal focuses on the reuse of materials. Papers were invited that would highlight economic, social and environmental aspects of waste minimisation and the reuse of materials. The topic is wide and the papers submitted only provide a glimpse of the considerable scope in finding new uses for materials that would otherwise go to waste.

Finding new uses for waste materials requires not only the technical assessments of material properties, but also an appreciation of the commercial, environmental, legal and practical implications. In addressing the challenge of increasing recycling rates in the capital, London Remade has considered both the upstream and downstream aspects of the material flow. The March issue of the Journal made reference to the Demolition Protocol, ${ }^{4}$ commissioned by London Remade and launched at the Institution of Civil Engineers last November, and which aims to stimulate the supply and demand for recycled and recovered construction materials. The briefing note by Searles and Vaux in this issue describes the development of a sustainable market for recycled glass and notes the importance of raising awareness in key areas to stimulate the market.

Tyres, like glass, present a challenge for waste management, particularly with the scheduled ban on the disposal of shredded tyres to landfill by 2006. In the UK, 450000 tonnes of used tyres have to be reused or disposed of annually. The briefing note by Parry reports on research being undertaken into the development of asphalt and concrete products using alternative aggregates such as tyre-rubber crumb and processed waste plastic. The full research report, which is freely available through the internet, addresses the legal and commercial aspects as well as the preliminary results of trials.

The paper by Simm et al. presents an overview of material reuse in the context of coastal and river engineering. Tyres feature again, with two case studies reported for projects in Lincoln and East Sussex. The paper also describes the use of recycled timber in the reconstruction of Southend Pier and in particular the procurement approach adopted to satisfy client requirements.

Coastal engineering also features in the next paper in which Cooper considers marine sediments and the opportunities for reuse of otherwise waste material derived from navigation dredging activities. Cooper quotes case studies and draws attention to benefits and practical difficulties including the potential conflict of resource recovery with environmental regulation focused on nature conservation.

When tyres are recycled, one of the by-products is steel cord. The paper by Pilakoutas et al. examines the suitability of this fibre for reinforcement in concrete and concludes that not only would this use provide an environmentally benign way of dealing with the fibres, but the properties of the concrete reinforced with these fibres is comparable with that of concrete reinforced with industrially produced fibres.

Concrete itself may become waste following the demolition of structures. The paper by Soutsos et al. examines the potential for re-use of construction and demolition waste for use in 
building blocks. The authors identify considerable opportunities in the regeneration of Liverpool, where the demolition of tower blocks could provide feedstock for aggregate to be used in the manufacture of concrete building blocks. There is, of course, also significant reuse of construction and demolition waste for low value uses such as road sub-base, but the research describes attempts to find a higher value reuse.

The paper by Padfield et al. also addresses aggregates produced from waste materials. The principal waste considered in this paper is a quarry waste, hassock sand, which when blended with other appropriate solid waste can be pelletised by cementation in a carbon dioxide rich atmosphere. The research, driven by the need to identify reuse options for waste materials, examined not only the material properties of the aggregate pellets but also the economics of the technology.

The rate of recovery of bricks for reuse in the UK is low. Gregory et al. assess the situation and point to the benefits of greater rates of reuse. However, the authors also acknowledge that improved technology will be required in order to achieve the improved rates of recovery.

Sassi reports on surveys undertaken in industry regarding attitudes towards the reuse of materials. She promotes a design approach that would enable subsequent dismantling and reuse or recycling of component elements and materials. Sassi argues that the hierarchy of 'reduce, reuse, recycle' may at times need to be reconsidered. Materials that can be recycled repeatedly provide a longer life expectation than specific productsespecially plastic items — with limited potential for reuse.

The final paper in this issue presents a case study putting a number of the waste minimisation and material reuse ideas in context. Bartlett et al. describe the waste neutral strategy of the Eden project in Cornwall, and identify improvements that have been introduced following lessons learnt from early construction contracts. The objective in both construction and operation is to reuse and recycle as much material as possible that would otherwise be waste.

There is no doubt that the potential for reuse of materials is significant. There is no doubt, either, that guidance in this field is considerable. Databases have been compiled and information is available from the Waste and Resources Action Programme as well as organisations such as Envirowise, Construction Industry Research and Information Association, Viridis and Building Research Establishment. A number of tools and guidance are available to assist the construction industry in improving its efficiency in the use of resources. The construction industry's track record in material reuse may well be summarised in that well worn phrase 'must do better', but then, as far as waste minimisation is concerned, that phrase can be directed at all sectors of our society.

\section{REFERENCES}

1. Sustainable DeVelopment Commission. Shows promise. But must try harder. SDC, London, 2004.

2. Institution of Civil EngineERs. The State of the Nation 2004. ICE, London, 2004.

3. DePARTMENT OF TRADE AND Industry. Site Waste Management Plans. Guidance for Construction Contractors and Clients. Voluntary Code of Practice. DTI, London, 2004.

4. Crudgington A. News from the ICE Waste Management Board. Proceedings of the Institution of Civil Engineers, Engineering Sustainability, 2004, 157, No. 1, 7-8. 